\title{
Disordering Gender Identity: Gender Identity Disorder in the DSM-IV-TR
}

\author{
Arlene Istar Lev, LCSW, CASAC
}

\begin{abstract}
SUMMARY. The inclusion of Gender Identity Disorder and Transvestic Fetishism in a psychiatric diagnostic nosology is a complex topic that is best understood within the larger context of the history and politics of diagnostic classification systems. The diagnostic labeling of gender-variant individuals with a mental illness is a topic of growing controversy-within the medical and psychotherapeutic professions and among many civil rights advocates. An overview of both sides of this controversy is outlined, highlighting questions about the potential damage caused by using psychiatric diagnoses to label sexual behaviors and gender expressions that differ from the norm, and the ethical dilemmas of needing a psychiatric diagnosis to provide legitimacy for transsexu-
\end{abstract}

Arlene Istar Lev is a social worker, family therapist, and educator addressing the unique therapeutic needs of lesbian, gay, bisexual, and transgender people. She is the founder of Choices Counseling and Consulting in Albany, New York, and on the adjunct faculties of S.U.N.Y. Albany, School of Social Welfare, and Vermont College of the Union Institute and University. She is the author of The Complete Lesbian and Gay Parenting Guide (Penguin Press, 2004) and Transgender Emergence: Therapeutic Guidelines or Working with Gender-Variant People and Their Families (Haworth Press, 2004) and also a Board Member of the Family Pride Coalition.

Address correspondence to: Arlene Istar Lev, LCSW, CASAC, Choices Counseling and Consulting, 321 Washington Avenue, Albany, NY 12206 (E-mail: info@ choicesconsulting. com) (Website: www.choicesconsulting.com).

[Haworth co-indexing entry note]: "Disordering Gender Identity: Gender Identity Disorder in the DSM-IV-TR." Lev, Arlene Istar. Co-published simultaneously in Journal of Psychology \& Human Sexuality (The Haworth Press, Inc.) Vol. 17, No. 3/4, 2005, pp. 35-69; and: Sexual and Gender Diagnoses of the Diagnostic and Statistical Manual (DSM): A Reevaluation (ed: Dan Karasic, and Jack Drescher) The Haworth Press, Inc., 2005, pp. 35-69. Single or multiple copies of this article are available for a fee from The Haworth Document Delivery Service [1-800-HAWORTH, 9:00 a.m. - 5:00 p.m. (EST). E-mail address: docdelivery @ haworthpress.com].

Available online at http://www.haworthpress.com/web/JPHS

(C) 2005 by The Haworth Press, Inc. All rights reserved.

$$
\text { doi:10.1300/J056v17n03_03 }
$$


als' right to attain necessary medical treatments. The author reviews the use of diagnostic systems as a tool of social control; the conflation of complex issues of gender identity, emotional distress, sexual desire, and social nonconformity; the reification of sexist ideologies in the DSM; the clinical and treatment implications of diagnosing gender for "gatekeepers"; and some recommendations for GID reform. [Article copies available for a fee from The Haworth Document Delivery Service: 1-800-HAWORTH. E-mail address: <docdelivery@haworthpress.com> Website: <http://www.HaworthPress.com> () 2005 by The Haworth Press, Inc. All rights reserved.]

KEYWORDS. Diagnosis, Diagnostic and Statistical Manual, DSM, GID, gender, gender identity, Gender Identity Disorder, psychiatry, stigma, transgender, transsexual

The inclusion of Gender Identity Disorder within the official diagnostic nosology of mental disorders is a controversial topic that invokes many questions about the role of the psychiatric establishment in the labeling of those who violate societal norms, particularly norms involving sex and gender issues. These questions are not unique to Gender Identity Disorders but involve a larger contextual analysis of the historical role of politics in the construction of diagnostic classification systems, and the medico-psychiatric (mis)treatment of those labeled with unusual sexual behaviors or gender expressions.

The Diagnostic and Statistical Manual of Mental Disorders (DSM) delineates the authoritative nomenclature of psychiatric nosology within the western world. The DSM is not a static document, but continues to evolve through text revisions and advanced scientific knowledge (Bartlett \& Vasey, 2001; Bower, 2001; Zucker, 2005). The current publication is the fourth text revision (APA, 2000) and includes both the diagnoses for Gender Identity Disorder (GID), the official diagnosis for transsexualism, and Transvestic Fetishism (TF), the official diagnosis for erotic transvestism, within the section on Sexual and Gender Identity Disorders. The diagnosis of GID, following a thorough psychosocial assessment and evaluation, is essential in order to receive a referral to a physician who can prescribe hormones, a necessary step to begin a medical sex reassignment process.

The DSM, undoubtedly the clinical "bible" of the psychiatric, psychological, and social work fields, is not, however, without its critics. 
Numerous academics, theoreticians, clinicians, researchers, and social commentators have levied accusation at the DSM for being over-inclusive, arbitrary, imprecise, lacking reliability and validity, being a tool for managed care and insurance companies, and for contributing to a pathologization of normal human diversity (Brown, 1994; Caplan, 1995; Kirk \& Kutchins, 1997; Szasz, 1970; Wakefield, 1997). The inclusion of GID and TF in the DSM has become the focus of a complex controversy regarding the purpose and use of the diagnostic systems in labeling people who express sexual and diversity. On one hand, the diagnosis invokes challenging questions about the use of psychiatric diagnoses to label as mentally ill those with sexual behaviors and gender expressions that differ from the norm, and on the other hand, raises equally compelling questions about the ethics of using a psychiatric diagnoses within a manual of mental illness to provide legitimacy for transsexuals' right to attain necessary medical treatments.

The DSM stresses that a mental disorder must " . . . be considered a manifestation of a behavioral, psychological, or biological dysfunction in the individual. Neither deviant behavior (e.g., political, religious, or sexual) nor conflicts between the individual and society are mental disorders unless the deviance or conflict is a symptom of a dysfunction in the individual" (APA, 2000, p. xxxi). The DSM does not offer clear guidance, however, in distinguishing deviant behavior that is caused by a psychiatric disturbance from socially non-conforming, but mental sound, deviant behavior (Kirk \& Kutchins, 1997; Wakefield, 1997). The DSM also does not offer a definition of mental health, or functionality, although the authors of the DSM acknowledge the limitations of their definition of mental illness and the difficulties of developing a consistent operational language for defining behavior that is "disordered," "abnormal" or "dysfunctional." However, the consequence and impact of this ambiguity on individuals who express "deviant" political, religious, and especially sexual lifestyles has been under-examined.

\section{DIAGNOSIS AS A TOOL OF SOCIAL CONTROL}

Diagnostic classification systems are presumed to rely on scientific study and positivistic research; diagnostic manuals are supposed to represent an expert and unbiased methodological perspective. The history of diagnosis in western cultures reveals bias and prejudicial assumptions that belie these expectations, and exposes an underlying psychomedical gaze that has intentional sought out human deviance with the 
intention of establishing institutionalized social control (Foucault, $1965,1978,2003)$. The psychiatric field has a long history of using diagnostic classifications to pathologize ordinary human diversity in the realms of race, ethnicity, sex, gender, class, disability, and sexual orientation, and being labeled psychologically deviant has inevitable consequences for the civil rights and social status of minority peoples (Brown, 1994; D’Emilio, 1983; Kutchins \& Kirk, 1997; Somerville, 2000). In the mid 1880s there was an explosion of anthropological, sociological, psycho-medical, and judicial explorations into abnormal sexual behavior, with a specific focus on libidinous desire, particularly in women and children, and sexual deviations, like inversion (cross- gendered homosexuality) and hermaphroditism (intersexuality) (Dreger, 1998; Foucault, 1965, 1978, 2003; Herdt, 1994). Many of the diagnoses in the current DSM are the legacy of these early explorations into human sexual deviations from what was presumed common and "normal," despite Kinsey's subsequent research showing enormous human diversity in sexual expression and behavior, raising questions about "normalcy" and actual human sexuality (Kinsey, 1948, 1953). The examples outlined below will reveal an aspect of societal regulation and attempts at political control inherent in classification systems, and how this impacted the development of a psychiatric hegemony over acceptable subjectivities, i.e., the defining of mentally disordered sexual and gender expressions that were therefore socially and legally unsanctioned.

According to scientific and medical experts of the 1800s, immigrants to the US-particularly the Irish-were thought to be more prone to mental illness, criminality, and other forms of social deviance. Italians, Slavs, and Jews were believed to suffer from serious mental illnesses based on a biological heredity that was said to "degenerate" with each successive generation (Bell, 1980). Benjamin Rush, known as the father of American psychiatry, believed dark African skin was caused by a medical illness related to leprosy; he also believed that people who had a fervent commitment to mass participation in democracy suffered from a mental illness called anarchia (Bell, 1980; Kutchins \& Kirk, 1997). Two common mental disorders of the 1800s were drapetomania, a mental illness among African slaves whose primary symptom was trying to escape slavery, and dysathesia ethiopica, used to describe slaves who destroyed plantation property, who were disobedient, who fought with their masters, or who refused to work (Kutchins \& Kirk, 1997).

These diagnoses could be viewed merely as odd historical footnotes, but in fact they have impacted law and public policy in profound ways. 
These diagnoses were used to support the need for slavery and racial segregation as well as setting strict quotas on the immigration of various European and Asian groups (Bell, 1980; Kirk \& Kutchins, 1997). Additionally, they provided the political support for anti-miscegenation laws which prohibiting marriages between races and sterilization laws to allegedly stop the spread of insanity, directed exclusively at minority peoples (ibid). In contemporary Western cultures, books are still marketed to "prove" the inferiority of black people's intellectual functioning (Herrnstein \& Murray, 1994), and research has shown that clinicians tend to ascribe more violence, suspiciousness, dangerousness, and psychological impairment to black clients than they do to white clients (Jones, 1982; Loring \& Powell, 1988); Blacks and Hispanics continue to be diagnosed with schizophrenia more frequently then whites (Wade, 1993). Racist underpinnings remain active in scientific study, in clinical assessment, and in the use of nosologies (consciously or unconsciously) to label minorities with mental health disturbances.

Just as medical diagnoses reinforced racist policies, they were similarly used to label women with mental health disturbances. From the mid 1800s through the twentieth century, women were diagnosed with neurasthenia, nervous prostration, dyspepsia, and hysteria, which were believed to be due to the "wandering" of the uterus within women's bodies (Ehrenreich \& English, 1978, 1973). Women were subjected to institutionalization in mental asylums, clitoridectomies, hysterectomies, removal of their ovaries, leeches applied to their labia, and forced rest cures based on these diagnoses (Geller \& Harris, 1994). When women began advocating for increasing social and political rights, medical experts evoked frightening pronouncements about the impact this might have on society. Women were accused of having a disorder called andromania, "a passionate aping" of "everything mannish." It was feared that if women won the right to vote, it would "make them change physically and psychically and pass along pathologies to their children" (as cited by Katz, 1995, p. 89).

A more contemporary example of sexism was the invisibility of the impact of childhood sexual abuse, adult sexual assault, domestic violence, and other trauma on the lives to women before the rise of second wave of women's liberation, and how their symptoms of abuse and trauma were misdiagnosed as masochistic behavior and Borderline Personality Disorder (Brownmiller, 1975; Herman, 1992; Miller, 1994; Schechter, 1982). Early feminist research showed how traits that were considered specific to women were believe to be less healthy than male traits, and but when women presented with more traditional male 
traits they were also thought to be mentally substandard (Broverman, Broverman, Clarkson, Rosenkrantz, \& Vogel, 1970). Contemporary feminist researchers and clinicians continue to expose the overuse of psychotropic medications in treating women, and the mislabeling of women's propensity for affiliation and connection to others as signs of codependency (see Mowbray, Lanir \& Hulce, 1985 Brown, 1994).

Caplan (1995) describes the debate over the addition of Premenstrual Dysphoric Disorder in the DSM-IV despite controversies over the lack empirical basis for the category, and the social and political consequences it may infer for women. Self-Defeating Personality Disorder (formerly called Masochistic Personality Disorder) was removed from the DSM following political pressure from prominent feminist researchers (Caplan, 1995). Criticisms continue to be levied at the diagnoses of Borderline Personality Disorder and Dissociative Identity Disorder, which are disproportionately seen in women who are victims of trauma; these diagnoses downplay the etiology of the disorders, placing the cause on dysfunction with the personality of the trauma survivor (Caplan, 1995; Herman, 1992; Kutchins \& Kirk, 1997; Miller, 1994).

The relationship between social mores and diagnostic processes is exemplified in the inclusion and subsequent removal of Homosexuality from the DSM (Bayer, 1981). Homosexuality initially appeared in the DSM-I under the label of sociopathic personality disturbance (APA, 1952), and was listed in the DSM-II as a Perversion (APA, 1968). Etiological theories of homosexuality prevalent before the 1970s were based on non-representative clinical or incarcerated populations (D'Emilio, 1983) and assumed that all homosexuals suffered from psychopathology (Smith, 1988). Evelyn Hooker's 1957 report of a non-clinical sample of homosexual men suggested that a significant portion of homosexual men showed no significant psychopathology, functioned well, and were satisfied with their sexual orientation (D'Emilio, 1983). In 1973, Homosexuality was removed from the DSM II (7th printing) because it failed to meet the criteria for distress, disability, and inherent disadvantage (APA, 1980; Bayer, 1981; Stoller et al., 1973). According to Bartlett and Vasey (2001), it was this controversy over removing Homosexuality from the DSM that compelled the writers of the DSM to develop a definition of mental disorders.

It is important to note that Homosexuality was not technically removed, but rather modified, and appeared in the DSM III as Egodystonic Homosexuality (APA, 1980, p. 282), which referred to the subjective experience of unhappiness and contrasted with syntonic behavior or one's comfort with their same-sex desires. This diagnosis was 
also eventually modified in the DSM-III-R (revised) due to the difficulty of disentangling the dystonia regarding sexual behaviors and desires from the societal condemnation resulting from these experiences. In explaining the decision, the compliers of the DSM explained, "It suggested to some that homosexuality itself was considered a disorder ... [and] ... almost all people who are homosexual first go through a phase in which their homosexuality is ego-dystonic" (APA, 1987, p. 426). It is further worth mentioning that a residual category for homosexuality still remains in the fourth text revision of the DSM, under the category of Sexual Disorders Not Otherwise Specified [NOS]. This category includes three items, the last one is, "Persistent and marked distress about sexual orientation" (APA, 2000, p. 582), presumably not commonly used to treat heterosexuals who are unhappy with their sexual orientation. Interestingly, Homosexuality was removed from the DSM in the same revision that a Gender Dysphoria Syndrome was first included (Whittle, 1993). Although it is unlikely that this was a purposeful (i.e., conscious) maneuver to maintain a way to diagnosis homosexuals (Zucker, 2005), it has nonetheless been continually used to pathologize lesbian, gay, and bisexual people, and particularly youth.

It is not to hard to see that social biases still drive the creation and maintenance of current diagnostic categories. These examples (and there are many more) of racism, sexism, and homophobia dressed up as science continue to impact clinical assessment and public policy in profound ways. The preceding discussion illustrates how clinical diagnoses have been used to (mis)label the ego-dystonic pain minorities experience, as well as their attempts to stand up to oppressive situations, as descriptions and proof of their mental disorders. These diagnoses then influence repressive social policies and judicial decision-making that further institutionalize these bigoted and oppressive polices. Clinically the question is raised whether the "deviance," "conflict," or "disorder" that women, people of color, and sexual minorities have experienced are, in fact, symptoms of a "dysfunction in the individual"-as the definition for mental disorders in the DSM maintains is necessary for a diagnosis to be made (APA, 2000, p. xxxi, emphasis mine)-or an adaptation to untenable and abusive social and clinical paradigms. The answers to this question pose potential ethical dilemmas for clinicians, who are imbued with the power to label, and therefore influence social justice and legal opinions; these are the issues underlying the current debate of the DSM diagnoses of Gender Identity Disorder and Transvestic Fetishism. 


\section{THE DIAGNOSIS OF GENDER}

Cross-gender identity has not always been pathologized, and evidence of gender variant expression has existed cross-culturally and throughout history (see Blackwood \& Wiering, 1999; Bullough \& Bullough, 1993; Coleman, Colgan \& Gooren, 1992; Herdt, 1994; Newman, 2002; Roscoe, 1998). Definitions and descriptions of sex and gender differences vary across cultural contexts, and are interpreted in complex and assorted ways within different scientific epochs (Dreger, 1998; Fausto-Sterling, 2000). As Newman (2002) has said, "wide variations exist in beliefs about the nature of biology and what constitutes sex" (p. 354), showing that even scientific facts about embodiment exist within cultural paradigms and perspectives. Although gender variant people appear to represent a small, but stable expression of human diversity, social views and treatment of gender-variant behavior and cross-gender expression vary extensively across cultures and historical settings. In Western cultures, however, sexed bodies and gender expressions are severely proscribed, assigned, and delineated and deviations from these norms are classified within the sphere of the medical and psychiatric establishments.

The psychiatric diagnoses of GID and TF, as they are currently outlined, erroneously conflate complex issues of gender identity, emotional distress, sexual desire, and social nonconformity. In deconstructing these diagnoses, four areas will be examined to make a case for GID reform. First, diagnoses related to gender issues are based on classification systems that seek to type and subtype gender variant people in order to determine who is "really" transsexual and only those who fit certain narrow criteria are deemed eligible for further medical treatments. Second, the diagnostic criteria for GID conflates those who suffer from gender dysphoria with those who desire sex reassignment, and therefore does not allow for the existence of healthy, functional transsexuals and transgender people who are able to seek medical and surgical treatments for their own actualization without being labeled mentally ill. Concurrently, the diagnostic criteria of GID and TF does not adequately delineate the distress and dysphoria some gender variant people experience, but the criteria outline descriptions of cross-gender behavior and assume the emotional pain is related to the cross-gender identity rather than to the social and psychological consequences of having a stigmatized identity. Additionally, GID is used to diagnose children and youth with cross-gendered behavior, who are then treated to prevent adult homosexuality and transsexualism, raising complex moral and ethical 
questions about the use of DSM as a tool of the social control of children and youth. Finally, the diagnostic criteria of both GID and TF are based in stereotypical sexist and heterosexist assumptions regarding normative male and female experience, as serves to reify a traditional gender-based hegemony.

\section{Classification Zeal and the Diversity of Gender Expressions}

The diagnostic classification of gender related disorders in the DSM is based on nearly forty years of research and clinical analysis originating with the seminal ideas of endocrinologist Harry Benjamin (1966) who suggested that transsexuals could not adjust to their birth sex regardless of the psychotherapeutic intervention aimed at curing them. Benjamin described people with gender dysphoria as representing a continuum of behaviors and experiences with transsexualism at one end and transvestism at the other, expressing two distinct "types" of gender dysphoria. Transsexuals were identified as people who had life-long cross gender-identity dysphoria, lack of erotic crossdressing, strong dislike for their genitalia, a persistent desire for sex reassignment surgery, and a sexual attraction to those of their same natal (birth) sex. Transvestites, on the other hand, were defined as heterosexual males, who have a primarily male gender identity and who cross dress for erotic reasons but expressed no desire for SRS (see Bentler, 1976; Buhrich \& McConaghy, 1977b; Freund, Steiner, \& Chan, 1982; Michel, Mormont, \& Legros, 2001).

According to this model, only "true" or "primary" transsexuals should be eligible for medical and surgical treatments and distinguishing between "true" transsexuals and all other gender variant and gender dysphoric people became the focal point of much of the research as well as clinical evaluation. Using Benjamin's theories as the model for understanding gender dysphoria, gender specialists developed complex classification systems to distinguish different types and subtypes of gender variant behaviors. Different researchers focused on different aspects of behavior or history, i.e., sexual orientation, fetishism, mental health status, age of onset, etc., that they saw as salient to the etiology or diagnostic categorization of transsexualism (see Blanchard, 1985; Blanchard, Clemmensen \& Steiner, 1987; Buhrich \& McConaghy, 1977a, 1997b, 1979; Johnson \& Hunt, 1990; Person \& OVasey, 1974a, 1974b, 1976, 1984; Levine \& Lothstein, 1981; Levine, 1993; Roback \& Lothstein, 1986; Wise \& Meyer; 1980). 
Delineating between "true" transsexuals and other gender variant people became paramount due to the seriousness and irreversible nature of sex reassignment procedure. The meticulous focus on classification has been justified because following strict criteria was determined to result in the most successful gender transitions (Landén, Wålinder, Hambert, \& Lundström, 1998; Walinder, Lundström, \& Thuwe, 1978). Although the DSM does not use the language of "true transsexualism," and in the past twenty years a greater range of gender variance has been recognized, the diagnosis of GID is still based in this model of distinguishing various "types" of gender variance, to determine eligibility. For example, the DSM distinguishes GID from the diagnosis of Transvestic Fetishism, indeed eroticized cross-dressing in natal males has been considered a sign of a poor prognosis for medical procedures and a TF diagnosis has historically rendered one ineligible for medical treatment. However, many erotic cross-dressers not only desire medical treatment, but also persistent in their pursuit of it, leading King (1993) to say, "Transvestites requesting sex changes were a professional headache ..." (p. 53). Equally challenging was the question of "secondary transsexuals" (Person \& Ovesey, 1974b), who appeared to age into a transsexual pattern following a life-long erotic crossdressing pattern.

Complicating this already complex attempt to delineate types and subtypes of gender variance, Blanchard (1989a, 1989b, 1991, 1993a, 1993b) has hypothesized that the primary motivation of a subset of male gender dysphoric people is their experiencing erotic excitement from the fantasy of possessing female anatomy. Autogynephilia, as he labeled this subtype of gender disorder, is now a diagnostic associated feature of GID in the DSM-IV-TR. Linkage of transsexualism to sexual eroticism has resulted in vigorous debates and hostile disagreements among clinicians as well as within the transgender community (see Allison, 1998; Lawrence, 2005), raising the question of whether those with gender-related paraphilias should be eligible for sex reassignment.

The classification zeal exhibited by researchers probably correctly identifies various patterns and subtypes of crossgender experience, and points to multi-variant etiologies in the development of transgender experience. This older medical model of understanding transsexualism and gender dysphoria contributed to the establishment of Gender Clinics and development and availability of medical procedures, as well as supported an outpouring of research and clinical discussion (Denny, 2004); in essence it legitimized gender transposition as a valid human concern, with available medical and psychiatric treatments. Evaluative procedures have continued to evolve and these narrow descriptions of 
transsexuality have been replaced by broader and more inclusive eligibility requirements (Meyer et al., 2001), although these older models still greatly inform clinical perspectives and research directions.

The medical model has, however, left a problematic legacy by reinforcing the gender binary and therefore legitimizing only certain kinds of gender dysphoric people, and eliminating, or severely restricting, access to medical treatment for people whose gender-variant expression follows atypical patterns (Denny, 2004; Lev, 2004). Only one narrative was acceptable to receive treatment, and those who desired treatment knew they must present that narrative if they wanted therapeutic approval, regardless of whether it was an accurate reflection of their experience (Bolin, 1988; Lev, 2004, Prosser, 1998; Stone, 1991). Unfortunately, other narratives became silenced, rendering alternative stories about gender-variance and cross-gender experience invisible, because to tell the truth about one's gender experiences, if it deviated from the approved outline of the medical model, was to become ineligible to treatment. Those who sought treatment through Gender Clinics became the "standard" gender-variant people, and all others became gender outlaws (Bornstein, 1994; Denny, 1992).

Those who fit the diagnostic criteria of GID are only a small segment of gender variant people potentially seeking treatment. Despite the thorough and painstaking attempts of gender researchers to classify gender variance, it has become obvious in the last decade that many people simply do not fit into the categories that have been delineated, and yet still seek medical and surgical treatments (Lev, 2004). Carroll (1999) said, "Increasingly clinicians and transgender individuals themselves are finding that these categories are inadequate to describe the possible resolutions to cross-gender experience" (p. 129). The criteria that have been set forth in the DSM do not accurately describe the full spectrum of gender variance experienced in the lived lives of gender dysphoric and gender-variant people seeking medical treatments (Denny, 2004; Lev, 2004). The vast majority of research has focused on studying natal males who apply for treatments through approved Gender Clinics and those who were active in transvestite-type clubs (Bullough, 2000)-information is now being revealed about previously hidden populations, for example FTMs, trans-identified butches, genderqueer and other transgender populations only recently emerging because of the advent of the Internet (Lev, 1998; Lev, in press; Nestle, Wilchins, \& Howell, 2002; Shapiro, 2004; Whittle, 1998).

Under the rubric of the transgender umbrella are included numerous natal females for whom the extant classification systems have always 
been an imperfect fit; this includes many female-to-male transsexuals, transgender females who are seeking hormones to virilize their bodies, or perhaps desire breast reduction/chest reconstruction, but without full SRS, as well as those who identify as transgender butches (see Chivers \& Bailey, 2000; Cromwell, 1999; Devor, 1997a, 1997b, 1998; Eyler \& Wright, 1997; Green, 2001, 2004; Halberstam, 1998; Hale, 1998; Lev, 1998; Rachlin, 1999; Rubin, 2003). Also included are both heterosexual and homosexual males who cross dress and desire hormones for feminization but do not desire genital surgery; some of these males may work as men and live as women the rest of their lives, live fulltime as women, or perhaps only occasionally cross dress for eroticism, comfort, or "camp" (i.e., entertainment) (Money \& Lamacz, 1984; Doctor \& Prince, 1997). Also noted in the literature are she/males who desire to mix male and female body parts (Blanchard, 1993a), and cases where people desire body changes without the associated need to change their sex, i.e., a man who requested female hormones to enlarge his breasts, but requested no other physical changes (Kremer \& den Daas, 1990). Additionally, there are many people who desire to not seek out medical treatment, but identify as the "opposite sex," or appear to others to belong to the opposite sex, and who may experience some level of gender dysphoria (Devor, 1989, 1997b; Lev, 1998; Rubin, 1992). Of particular note is the more recent recognition of female-to-male gay transsexuals, a "subtype" previous invisible within the literature, debunking the mythology that all FTMs were lesbian before transition, and heterosexual post-transition (Clare \& Tully, 1989; Blanchard, Clemmenson, \& Steiner, 1987; Coleman \& Bockting, 1988; Coleman, Bockting, \& Gooren, 1993; Devor, 1998; Dickey \& Stephens, 1995; Rosario, 1996).

One of the more interesting developments over the past decade has been the emergence of transgender people who define themselves as bigendered, mixed gendered, dual gendered, gender-blended, or genderqueer and may seek medical treatments to help accentuate masculine or feminine characteristics, but do not desire complete sex reassignments (see Ekins \& King, 1998; Gagné, Tewksbury, \& McGaughey, 1997; McKain, 1993; Monroe, 2005; Nestle, Wilchins, \& Howell, 2002; Sell, 2001). Some see their dual gender as fluid, changing during their life, or during the course of a day; others see their gender as stable and consistent, but somewhere in the "middle" (see Bornstein, 1994, Boswell, 1998; Feinberg, 1998; Hooley, 1997; Tauchert, 2001, 1997; Wilchins, 1997). 
Researchers have long been interested in the sexual orientations of those who are crossgendered, and historically having the "correct" sexual orientation (i.e., heterosexual post-transition) was a determining factor in eligibility for medical treatment (Dallas, 1992). It is becoming increasingly evident that gender-variant people express diverse sexual orientations, and identify in unique ways that are outside of the traditional nomenclature (Bullough \& Bullough, 1997; Dallas, 1992; Daskalos, 1998; Denny \& Roberts, 1997; Cromwell, Green, \& Denny, 2001; Devor, 1997a; Lev, 2004). One area in need of greater exploration is the relationship between gender identity (as well as sexual orientation) across ethnic, racial and cultural boundaries; it is likely that experiences, expressions, and subjectivities are culture-specific, and only intelligible within an understanding of diverse cultural frameworks (Blackwood \& Wiering, 1999; Herdt, 1994; Newman, 2002; Roscoe, 1998; Rosario, 2004; Tarver, 2002).

Although it is perhaps interesting to note the various sexual preferences, behaviors, and identities that gender variant people express, it is worth asking whether these variables should be the basis for a clinical nosological system based in eligibility for medical services. The current GID diagnosis is a narrow description of transgender expression leaving out many distinct groups that are easily recognized in clinical practice (Seil, 2004). As Bockting (1997) has said, “. . . a paradigm shift has occurred signified by an emerging transgender consciousness that challenges the binary conceptualization of gender" (p. 49). In other words, although GID may describe some self-identified transsexuals, it does not describe the diversity of cross-gendered people who are seeking transsexual treatments.

\section{Disorder, Distress, and Mental Illness}

The theoretical underpinnings of all attempts to define, type, and delineate all non-conforming gender behavior have been based on the assumption that gender transgressions are by their nature mental disorders (Wilson, 2002). Indeed, the very name, Gender Identity Disorder, suggests that there is a normal non-disorder way for gender identity to be expressed, and that all other gender expressions can be compared to that, and found not only deficient, but diagnosably mentally ill. Langer and Martin (2004) say that "Cross-gender identification may in fact be statistically deviant, but there is no evidence that it is a dysfunction" (p. 11). 
Utilizing a mental illness model leaves no room for the recognition of mentally healthy and functional transgender and transsexual people who may desire sexual reassignment treatments. The GID diagnosis as it is currently constructed is problematic because it labels all gender-variant people as "disordered," including those who meet no other criteria for having a mental disorder and do not experience disorder or distress. Now, it may be true that the desire for transition inherently assumes some level of distress, but having a clear sense of what is not working in one's life and how to address that would generally not require a DSM diagnosis. A person who is lonely and seeks out dating and courtship to meet a mate would not receive a diagnosis; for that matter, their ability to find a solution to their struggles might infer mental health and good coping skills.

Distress and impairment are the hallmarks for defining mental disorder in the DSM for both GID and TF. Distress can include impairment in social or occupational functioning, which poses an interesting dilemma since social and occupational problems are often directly related to the pathological nature of the diagnosis. A person may experience marital problems, social rejection, job loss, and legal problems due the impact of their gender dysphoria and/or the decision to transition sex on others which consequently might cause distress, dysfunction, or impairment, and make them eligible for a mental health diagnosis. However, if gender-variant experience was not originally pathologized, perhaps people would experience far less social and occupational difficulties. The distinctions between distress that is within human beings and that which is externally imposed is not clearly delineated in this section (Wilson \& Hammond, 1996; Winters, this volume). Granted, he line between social injustice and individual pathology can be difficult to discern, since the stigma of cross-dressing and gender transitions can interfere with marital relations, as well as occupational stability, and in certain locales may have legal ramifications. However, these are consequences of gender oppression, not inherent to having a cross-gendered identity. In other words, the problems may not be caused by having a non-conforming gender expression, but rather by the social implications of actualizing them. If gender-variant behavior was not stigmatized by labeling these expressions as psychiatric diagnoses, then transgender and transsexual people might experience significantly less emotional, legal, or social distress.

The current diagnostic criteria for GID conflates those who suffer from gender dysphoria with those who desire sex reassignment, and therefore does not allow for the existence of healthy, functional trans- 
sexuals and transgender people who may seek medical treatment as a sign of their mental health, not a function of their mental illness.

\section{Treating Children for Future Homosexuality}

The GID diagnosis as it is currently written links adult transsexualism to gender identity issues for children and adolescents, although the evidence that they are etiologically or psychologically analogous in inconclusive. Research has consistently shown that many children diagnosed with GID often grow up to be, not transsexual, but homosexual (Bailey \& Zucker, 1995; Green, 1987; Rekers \& Kilgus, 1995; Zucker, 1990; Zuger, 1984). In fact, Zucker and Bradley (1995) note that for children diagnosed with GID " . . . homosexuality is the most common postpubertal psychosexual outcome" (p. 53). Many children who grow up to be lesbian, gay, or bisexual, acknowledge or remember cross-gender behavior in their own childhood (Bailey \& Zucker, 1995; Rottnek, 1999).

Treatment protocols that have been developed to treat children diagnosed with GID identify future homosexuality as one of the motivating forces (Bartlett \&Vasey, 2001; Green, 1987; Rekers \& Kilgus, 1995; Zucker, 1990; Zucker \& Bradley, 1995). Other reasons for treatment are also identified, including eliminating peer ostracism and increasing self-esteem, although methods to reduce school-related abuse are not mentioned (see Mallon, 1999). It is worth noting that in other areas where children are routinely bullied, for example racial or ethnic discrimination and physical or mental disabilities, the focus of intervention has been policy directed towards changing the social conditions that maintain abuse, not on changing children to better fit in to oppressive circumstances. Finally, researchers have justified treating children with GID because they are described as suffering from severe mental health problems which were thought to etiologically be related to parental psychopathology which had induced or maintained the child's cross-gender expression (Bradley \& Zucker, 1997; Coates, 1990; Coates, Friedman, \& Wolfe, 1991; Coates \& Person, 1985; Rekers \& Kilgus, 1995; Stoller, 1966, 1967, 1968a, 1968b; Zucker, 1990; Zucker \& Bradley, 1995; Zuger, 1970). It is unclear why the children are being treated, rather than parents who are identified as having mental health problems. Although it is certainly possible that children might acquire gender-related developmental issues depending on a parent's mental health issues, it is equally true that having a child with gender issues can cause marital discord and concurrent psychological issues (Lev, 2004). 
Di Ceglie (et al., 2002) notes the most common problems seen in children referred for treatment are difficulties in intrafamilial and other relationships; it is possible that these difficulties are not causal of the child's cross-gendered expression, but rather its sequelae. It is also important to note that the child need not be disturbed by his or her own cross-gender behavior to be eligible for treatment; it only needs to be disturbing to adults (Mallon, 1999; Benestad, 2001).

GID can be, and is often, utilized by clinicians who still view homosexuality as a treatable mental illness (Nicolosi, 1991; Socarides, 1999). Over thirty years after homosexuality was removed from the DSM, lesbian, gay, and bisexual people, particularly youth who are considered "pre-homosexual," are still pathologized under another diagnostic category, GID, and treated within the psychiatric profession to change their sexual orientation (for further discussion see Burke, 1996; Corbett, 1998; Isay, 1997; Mallon, 1999; Rottnek, 1999).

Although Zucker does not promulgate preventing homosexuality alone is a valid goal for treatment, he does state that whether the focus of treatment is on the elimination of peer ostracism in childhood or the prevention of transsexualism in adulthood they are both " . . so obviously clinically valid and consistent with the medical ethics of our time that either, by itself, would constitute sufficient justification for therapeutic intervention" (Zucker, 1990 p. 30). Green also upholds GID treatment of children stating that parents have a right to insist on treating cross-gender behavior in childhood with the hope of warding off adult homosexuality even though he admits that "... there is no convincing data that anything the therapist does can modify the direction of sexual orientation" (1995, p. 2014).

Cohen-Kettenis (2001) suggests that the GID diagnosis should be maintained in the DSM because children can begin earlier sex reassignment with proper identification, assessment, and treatment. Indeed, early identification of gender dysphoria in young children might be diagnostically useful for the purpose of early treatment, but not treatment based in "curing" the dysphoria, but rather in helping young children cope with actualizing their gender within an often hostile social environment. Treatment protocols developed to help eligible young people transition have been very successful (see Cohen-Kettenis \& van Goozen, 1997) and clinicians should be asking how we can assist those young people who are likely to mature into transsexual and transgender people in healthy functional development. They may well be ways to identify these children, however, without diagnosing them with a mental illness. 


\section{The Clinical Reification of Sexism}

The basis for the diagnostic criteria in children rests in stereotypical definitions of "normal" male and female behavior, including pathologizing cross-gendered play and the preference of having playmates of the other sex. The DSM does not appear to recognize the impact of forty years of feminism, and the full range of behaviors and experiences engaged in by "normal" males and females in contemporary society. Despite its stated intention to not pathologize non-conforming stereotypic sex-role behavior, the criteria listed do exactly that. By stating that some gendered behavior in children is pathological, the DSM establishes a "fiction of natural gender" (Spade, 2003, p. 25), an assumption that there is normal and abnormal ways to express, that creates a policing and surveillance of correct gender behaviors in all children. Boys are, however, more frequently referred for assessment of gender disorders than are girls (Zucker \& Bradley, 1995; Cohen-Kettenis et al., 2003)and therefore more likely to receive treatment. In all likelihood this is because they are held to more rigid gender conformity in their dress and mannerisms and their transgressions cause more social difficulties (Rottnek, 1999). Although it is their atypical gender identity that has been identified as the problem, it is possible that their distress is related to the stigma of being different, indeed being referred to clinics and professionals to treat these differences, rather than their actual gender experiences or expressions (Lev, 2004).

Sexism and homophobia can also be found in the diagnostic criteria of Transvestic Fetishism, which has been "... described only in heterosexual males" (APA, 2000, p. 574). Is cross-dressing therefore "normal" when homosexual or bisexual men have fantasies or sexual urges to cross dress? Are females who crossdress exhibiting signs of mental health? Or are females exempt from being considered cross-dressers-even if they wear traditional men's clothing or feel "sexy" when they do so?-since there is less social regulation of female attire?

There is scientific evidence showing that $\mathrm{TF}$ is a rare occurrence in natal females (Långstöm \& Zucker, 2005). Rare does not mean non-existent, and there are potential methodological concerns that suggest that survey questions might not be correctly identifying the experience of females who crossdress. Since women and men likely experience their sexuality differently, the term "sexual arousal" might not accurately operationalize women's sense of "sexiness" regarding their clothing choices. Since women have much greater social access to traditional male clothing, it is likely that their experiences as "crossdressers" might 
not involve the same secrecy as most male crossdressers. Furthermore, lesbian literature, particularly within butch/femme communities, clearly outlines erotic crossdressing experience for butch-identified lesbians (as well as their partners) (Burana, Roxxie \& Due, 1994; Feinberg, 1993; Kennedy \& Davis, 1993; Nestle, 1992; Pratt, 1995), though the experience of this population of natal females is not reflected in the extant research.

Some research suggests that erotic cross-dressing is a behavior engaged in by people of all sexual orientations (Bullough \& Bullough, 1997) but yet it is when only heterosexual males crossdress that a label of mental illness is applied. This raises many questions about the social control purposes of gendered clothing. Could it be that heterosexual males are held to a different standard of behavior than females and homosexual males? As Wilson says, the DSM does not merely “. .. reflect the disparate positions that men and women hold in American society, but promotes them" (1997, p. 5).

The DSM (intentionally or otherwise) is reifying traditional gender roles. When men are labeled with mental illness for doing nothing more serious than feeling aroused wearing traditional women's clothing, and boys are labeled pathological for expressing "cross-sex roles in makebelieve play or .... [ [participating] in the stereotypical games and pastimes of the other sex, [preferring] playmates of the other sex, and . . simulating female attire" (APA, 2000, p. 581-2), however "persistent" or "intense" these interests may be, psychology has stepped over the edges of empiricism and into a role as harbingers of morality. This is not evidence-based research, but rather politics once again dressed up as science. A world where men can wear skirts and heels and boys can play with dolls may appear odd to some, but it is no more unusual than the world that has come to be in the past fifty years where women routinely wear pants and girls cannot only play boys' games, but they can play them in the real world as paid members of national basketball teams and manage billion dollar corporations. Societal prejudice and sexism-as well as the heterosexism that implicitly follows sexism (Pharr, 1988)should not be sanctioned and endorsed by the mental health community in the name of dubious science.

\section{CLINICAL IMPLICATIONS OF DIAGNOSING GENDER}

The development of the diagnostic category for transsexualism has been an important step in legitimizing gender dysphoria as a valid men- 
tal health concern. The formal recognition of gender identity disorders affirmed them "as conditions worthy of evaluation and treatment" and acknowledged sexual reassignment surgeries "as a legitimate treatment and not an elective or cosmetic surgery" (Pauly, 1992, p. 3). It is indeed accurate that the recognition of gender-variant people as a clinical entity deserving respectful mental health services, as well as the advances in the medical and surgical needs of transsexual and transgender people, can be directly linked to its prominence in diagnostic nosologies (Denny, 2004). However, that does not infer that Gender Identity Disorders really exist as mental illnesses-since it is unclear that the disorder resides within individuals rather than as a conflict with societal mores-although it is undeniable that including GID in the official nosology has brought some benefit and recognition to an underserved and disenfranchised community.

Reforming the diagnosis of GID is not intended to deny the deep pain and confusion often associated with gender variance within a dimorphic culture and the adjustment related issues that ensue (Lev, 2004). Some gender variant people suffer from profound distress and experience impairment and suffering related to identifying their gender related issues. Virtually all gender variant people struggle with confusion about their gender identity, frustration with attempts to fit into a socially prescribed binary of gender, and face decision-making regarding possible resolutions for their gender disturbances. If they pursue transition, they may additionally experience employment difficulties, marriage and family troubles, and social ostracism as well as struggles with self-esteem and ego integrity. The challenges facing transgender and transsexual people are enormous and this population is in great need of competent mental health services to address the adjustment related issues that result for having a cross-gender identity. The role of mental health clinicians in the treatment of transsexualism has too often been reduced to serving as evaluators for medical treatments, with few guidelines offered for other areas of therapeutic care.

In order to receive medical and surgical treatments gender variant people must first receive a referral from a mental health specialist who has completed a psychosocial evaluation. The evaluation must reveal a diagnosis of GID, i.e., a psychiatric illness, in order for the petitioner to obtain the desired referral. The tool commonly utilized for this psychological assessment is the guidelines of the Harry Benjamin International Gender Dysphoria Association Standards of Care for Gender Identity Disorders (Meyer et al., 2001); referral for medical services is offered to clients fitting the diagnostic criteria of GID in the DSM. Consequently, 
the diagnosis of GID has become an "admission ticket" for transgender and transsexual people seeking medical treatments. A psychological diagnosis is necessary to protect physicians from litigation, and also provides insurance companies with the means to determine inclusion (or, more commonly in the U.S., exclusion) for medical services.

The development of an authentic therapeutic relationship is severely impaired when the diagnostic evaluation casts the clinician in the role of gatekeeper who controls access to medical treatments. The client, who may be strongly motivated to pass through the gate, knows that being honest might impede this possibility. Clients requesting services are often familiar with the HBIGDA guidelines (Denny \& Roberts, 1997) as well as the diagnostic criteria of GID, and since approval for medical treatment rests on one's conformity to the diagnostic criteria, there is strong desire on the part of transgender client to "fit" the criteria outlined. Those clients who do not fit the criteria for GID but who desire medical and/or surgical treatments, are placed in an untenable position: they must risk rejection from the mental health professional if they tell the truth about their experiences or identity, or lie to the therapist to receive treatment. Professionals have been aware since Benjamin's seminal work of the "story-telling" that clients do to receive treatment (Billings \& Urban, 1982; Bolin, 1988; Bower, 2001; Hausman, 1995; Lewins, 1995; Prosser, 1998; Walworth, 1997), and it is mentioned in the HBIGDA Standards of Care as a potential impediment to the assessment process (Meyer et al., 2001).

The gatekeeping system requires that people who desire medical treatments have the same standardized autobiography since crossgendered people cannot simply request services, but must be fit a proscribed narrative to be eligible for services. Since the advent of the Internet there is an abundance of easily accessible information outlining how one should present to a therapist in order to receive approval. This "story-telling" therefore reinforces the model that has been outlined: those who are approved and pass through the gate have refined the same "transsexual narrative," validating it as the transsexual trajectory.

This gatekeeping system reinforces the development of a false relationship between therapist and client and some clinicians are developing advocacy-based models that allow room for alternative "stories" about cross-gender experience (see Cole et al., 2000; Bockting \& Coleman, 1992; Lev, 2004; Rachlin, 1997; Raj, 2002). These advocacy models allow gender specialists to move out of a gatekeeping model of assessment to a psychotherapeutic relationship that allows for a client's unique narrative and gender trajectory. These treatment philosophies 
and are based in a model of educated self-determination, where gender variance is respected, and clinicians serve as advocates and educators, as well as evaluators of mental health.

There are valid reasons for physicians requiring a psychosocial assessment before performing irreversible hormonal and surgical treatments on otherwise healthy human beings. Although most transgender people seeking services have a long history of gender dysphoria, and have done significant soul-searching before they sought out medical treatment, some people might seek treatment for gender issues who are actually are struggling with questions and confusion about sexual orientation. Others might have a bona fide mental illness rendering them incapable of logical thinking and decision-making, and still others may be unable to understand the nature of the medical treatments, and what they can-and cannot-actually accomplish. Some people have unrealistic expectations, or unresolved issues affecting their gender identity, and may not actually be good candidates for treatment. There are documented cases of gender dysphoric clients whose desire to transition remits (Marks, Green, \& Mataix-Cols, 2000). Psychotherapeutic evaluation and referral is used in making other medical decisions (i.e., infertility treatment) and since most physicians are not experts in mental health assessment, it seems reasonable that a trained mental health counselor should perform the evaluation. Referral however, should not have to depend upon a diagnosis of mental illness, but a successful evaluation of mental stability.

\section{REVISIONING GENDER: MEDICAL TREATMENT NOT MENTAL HEALTH DIAGNOSIS}

The removal of Homosexuality from the DSM allowed for the advancement of the gay civil rights movement and the subsequent public policy reformations regarding same-sex domestic partner benefits, and same-sex second parent adoptions, as well as the creation of a "gay-affirmative" counseling for lesbian and gay people that did not focus on curing homosexuality, but coping with the stigma and stress of being a minority (Robertson, 2004). Removing the stigma of psychopathology enabled legal and political transformations for gay, lesbian, and bisexual people that would never have been granted a "mentally ill" population (Lev, 2004). As Robertson (2004) has said, "it has had significant impact on the fate of thousands of individuals who in the past would have been deemed mentally ill" (p. 163). In the same way, emerging 
models that envision transgender people as mentally healthy and socially stigmatized have

... changed the locus of pathology; if there is pathology, it might more properly be attributed to the society rather than the gender-variant individual. . . . The transgender model holds that this societal mistreatment can result in psychological difficulties, including shame and guilt and resulting self-destructive behaviors, including abuse of alcohol and other drugs, eating disorders, and self-injurious behavior; dissociative conditions; personality and behavior disorders; and mood disturbances. Accounts under the older transsexual model tended to assume such problems were symptoms of or co-existent with the "syndrome" of transsexualism, discounting or more often never even considering that they might be reactions to societal discrimination and abuse. (Denny, 2004, p. 31)

The challenge regarding GID reform is that the current diagnoses of Gender Identity Disorder and Transvestic Fetishism (TF) reinforces the stigmatizing of gender variant people, and yet remains the only current avenue available for the medical actualization of transgender and transsexual identities. According to Butler (2004), GID reform invokes a paradox concerning autonomy. On one hand, there are transsexuals and other gender-variant people who seek sex reassignment, and in fact believe medical and surgical treatments are necessary for their actualization. They require the assistance of the medical field and, within the established system, cannot gain access to physicians without first achieving the approval of the clinical/psychiatric community. However, on the other hand, in order to be approved for the treatment they desire they must fit the criteria of a psychiatric illness, and prove themselves "sick enough" to receive the cure they desire. As Butler (2004) says,

... those who want to keep the diagnosis want to do so because it helps them achieve their aims and, in that sense, realize their autonomy. And those who want to do away with the diagnosis want to do so because it might make for a world in which they might be regarded and treated in non-pathological ways, therefore enhancing their autonomy important ways. (p. 77)

Autonomy, according to Butler, is socially conditioned, rendering the paradox of the diagnosis, both "enabling" and "restrictive" simul- 
taneously (ibid). Being labeled with GID can serve to alleviate human suffering, because the label will allow for the requested/ required treatment, and concurrently increases the same human suffering, by ensuring a definition and experience of one's gender experience as pathological and mentally deranged (Butler, 2004). The person seeking treatment must embrace the stigma of mentally illness or they are not eligible for the cure and " . . it is the treatment-seeking behavior of requesting sex reassignment that most often brings the gender disordered (sic) individual into contact with the health professional" (Baumbach \& Turner, 1992, p. 112). Doctor (1988) has suggested that transsexual surgery is "the only major surgical procedure carried out in response to the unremitting demands of the patient" (p. 25) and since medical and surgical treatment must be preceded by a diagnosis of GID, transsexuals may be one of the only populations actively pursuing a psychiatric diagnosis.

Removing GID from the DSM could, however, create havoc for transgender people since it would most likely eliminate all insurance coverage for medical treatments for transsexual persons. For those who depend on a DSM diagnosis for their self-actualization, a psychiatric diagnosis remains a small price to pay for to receive necessary treatments; paradoxically, those who can most benefit from the removal of a diagnostic category that pathologizes them have the most at stake in maintaining it (O'Hartigan, 1997). Removing GID from the DSM would reduce the regulatory aspect of gender transposition (i.e., increase autonomy) but could create a system whereby only those who are wealthy enough to afford out of pocket medical expenses for sex reassignment would be able to transition sex, potentially decreasing autonomy for all those but the rich (Butler, 2004).

The utilization of GID to confer eligibility for gender variant people who need medical treatments serves as a confirmation that transsexual and transgender people are suffering from disorder and dysfunction and invites questions about the ability of the DSM to distinguish between mental illness and social non-conformity. If the person does not exhibit distress or dysfunction, are they therefore ineligible for treatments they are requesting? If the person exhibits significant distress and dysfunction are the then too unstable to receive treatment? What are the ethical implications of labeling gender variant people who are mentally sound with a psychiatric diagnosis to justify their receiving medical treatments? Can a diagnosis of a mental illness do anything but set the stage for protocols designed to repair a dysfunction? 
Within the confines of these challenges, the diagnostic categories of Gender Identity Disorder and Transvestic Fetishism are continually undergoing text revisions and attempts at refinement (Bartlett \&Vasey, 2001; Bower, 2001; Cantor, 2002; Davis, 1998). Change, however, comes slowly, especially in the area of sexual disorders. Davis (1998), in her work with the NIMH Cultural and Diagnosis Sexual Disorder Work Group, states that despite the recognition of the importance of increased cultural considerations in the DSM, the recommendations of her committee were largely rejected and " . . . any challenge to the basic nosological assumptions that underlay the categories of sexual disorders themselves went unheeded" (p. 404).

However, GID reform remains necessary. The basic civil liberties for transgender and transsexual people will be elusive as long as gender variance itself is a mental illness; legal reform and psychiatric treatment are linked in complex ways (Weiss, 2004). Currently the battle for civil rights and justice rests on using the psychiatric diagnose to legitimize transsexuals, rather than de-regulating gender in the law (as has been done with racial categorizations), which will create broader gender rights for all gender-variant people (Spade, 2003). GID reform in the mental health field should include: the depathologizing of cross-gender experience; the recognition of transsexual trajectories based in mental health rather than on distress or dysfunction; the broadening of eligibility for medical referral to include those with non-transsexual gender variant experiences; attention to the role of heterosexism and sexism in generating the diagnostic criteria; and preventing the misuse of GID to treat alternative sexual orientations and gender expressions in children and youth. The task ahead is to reform GID in the DSM without eliminating clinical and medical treatments for transgender and transsexual people.

A number of possibilities at reform have been promulgated. Cantor (2002) suggest the utilization the diagnosis of Identity Problem (313.82) already listed in the DSM, which would remove the focus off of the gender aspects, and onto the identity issues that are paramount in sex reassignment. It is, however, questionable whether codes in this section-Additional Conditions that May be the Focus of Clinical Attention-would be insurance reimbursable. Other possibilities for those experiencing gender dysphoria and/or body dysmorphia is to create specific gender-focused diagnoses, with the emphasis being on the discomfort not the identity. Vanderburgh (2001) has recommended using the term Gender Dissonance and Winters (this volume) has suggested utilizing a diagnosis of Gender Dysphoria to distinguish 
distress with one's physiological sex from other aspects of gender role nonconformity that are not pathological.

In truth, there are many extant diagnoses that can be used that would eliminate the focus on the individual's cross-gender identity, and place it instead on their distress as the focus of treatment. Many gender-variant people seeking therapy are experiencing anxiety, dysthymia, depression and other DSM diagnoses, which can be used, without focusing on the gender issues as causative. Finally, in most cases where someone is seeking clinical assistance for a gender-related issue, even if they are only seeking a medical referral, a diagnosis of Adjustment Disorder on Axis I would adequately classify the reason for treatment.

An additional suggestion is to remove GID from the psychiatric nosology and use the already extant diagnosis of Transsexualism-described in the International Classification of Diseases, Tenth Edition (ICD-10), an Axis III medical condition-for medical treatments and reimbursement. The ICD diagnostic criteria would need to be revised and updated since they are based in a narrow view of transsexualism, but utilizing a diagnosis from a manual of physical ailments would validate the need for medical treatment without inferring a mental health diagnosis. Thus, gender transition would be an insurance reimbursable medical condition similar to pregnancy. Any mental health issues would be noted on Axis I or II as they would for any other psychological disorder, without mentioning the gender issues per se. A black person with an anxiety disorder does not receive a racially identifying diagnosis, nor does a gay man with alcoholism receive a diagnosis highlighting his sexual orientation. This is not to say that race or sexual orientation do not impact anxiety or alcoholism, or even in some cases explain or justify these symptoms; it is not, however, part of the diagnostic label.

The direction of reform will be a topic of debate among researchers and clinicians for decades to come. The DSM states clearly that neither deviant sexual behavior, nor conflicts between the individual and society are mental disorders unless the deviance or conflict is a symptom of a dysfunction within the individual. Having a gender identity, even a non-conventional one, is not a dysfunction within an individual, although it may cause psychosocial problems that need to be psychotherapeutically addressed, and it often requires medical treatment for the individual's self-actualization and their sense of congruence between their body and mind. Approval for medical treatment should not depend on being mentally ill, but on being mentally sound enough to make empowered and healthy decisions regarding one's body and life. 


\section{REFERENCES}

Allison, B. (1998). Janice Raymond and autogynephilia. Retrieved May 10, 2005, from: http://www.drbecky.com/raymond.html.

American Psychiatric Association (1952). Diagnostic and statistical manual: Mental disorders. Washington, DC: American Psychiatric Association.

American Psychiatric Association (1968). Diagnostic and statistical manual of mental disorders (Second Edition), Washington, DC: American Psychiatric Association.

American Psychiatric Association (1980). Diagnostic and Statistical Manual of Mental Disorders (Third Edition), Washington, DC: Author.

American Psychiatric Association (1987). Diagnostic and Statistical Manual of Mental Disorders. (Third Edition, Revised), Washington, DC: Author.

American Psychiatric Association (2000). Diagnostic and Statistical Manual of Mental Disorders (Fourth Edition, Text Revision), Washington, DC: Author.

Bailey, J. M. \& Zucker, K. J. (1995). Childhood sex-typed behavior and sexual orientation: A conceptual analysis and quantitative review. Developmental Psychology, 31(1), 43-55.

Bartlett, N. H., Vasey, P. L., \& Bukowski, W. M. (2000). Is gender identity disorder in children a mental disorder? Sex Roles, 43 (11-12), 753-785.

Baumbach, J. \& Turner, L.A. (1992). Female gender disorder: A new model and clinical applications. In W.O. Bockting \& E. Coleman (Eds.) Gender dysphoria: Interdisciplinary approaches in clinical management (pp. 107-129). Binghamton, NY: The Haworth Press, Inc.

Bayer, R. (1981). Homosexuality and American psychiatry: The politics of diagnosis. Princeton, NJ: Princeton University Press.

Benestad, E.E.P. (2001). Gender belonging: Children, adolescents, adults and the role of the therapist. Gecko: A Journal of Deconstruction and Narrative Ideas in Therapeutic Practice, 1 (8), 58-80.

Bell, L. V. (1980). Treating the mentally ill: From colonial times to the present. NY: Praeger.

Bentler, P. M. (1976). A typology of transsexualism: Gender identity theory and data. Archives of Sexual Behavior, 5, 567-584.

Billings, D. B. \& Urban, T. (1982). The socio-medical construction of transsexualism: An interpretation and critique. Social Problems, 29 (3), 266-282.

Blackwood, E. \& Wiering, S.E. (Eds.) (1999). Same-sex relations and female desires: Transgender practices across cultures. NY: Columbia University Press.

Blanchard, R. (1985). Research methods for the typological study of gender disorders in males. In B. W. Steiner (Ed.) Gender dysphoria: Development, research, management. (pp. 227-257). NY: Plenum.

Blanchard, R. (1989a). The classification and labeling of nonhomosexual gender dysphorias. Archives of Sexual Behavior, 18, 315-334.

Blanchard, R. (1989b). The concept of autogynephilia and the typology of male gender dysphoria. Journal of Nervous \& Mental Disease, 177, 16-623.

Blanchard, R. (1991). Clinical observation and systematic studies of autogynephilia. Journal of Sex and Marital Therapy, 17 (4), 235-251. 
Blanchard, R. (1993a). The she-male phenomenon and the concept of partial autogynephilia. Journal of Sex and Marital Therapy, 19 (1), 69-76.

Blanchard, R. (1993b). Varieties of autogynephilia and their relationship to gender dysphoria. Archives of Sexual Behavior, 22 (3), 241-251.

Blanchard, R., Clemmensen, L., \& Steiner, B. (1987). Heterosexual and homosexual gender dysphoria. Archives of Sexual Behavior, 16 (2), 139-152.

Bockting, W. O. (1997). Transgender coming out: Implications for the clinical management of gender dysphoria. In B. Bullough, V. L. Bullough \& J. Elias (Eds.), Gender blending (pp. 48-52). Amherst, NY: Prometheus Books.

Bockting, W. O. \& Coleman, E. (1992). A comprehensive approach to the treatment of gender dysphoria. In W.O. Bockting \& E. Coleman (Eds.) Gender dysphoria: Interdisciplinary approaches in clinical management. (pp. 131-155). Binghamton, NY: The Haworth Press, Inc.

Bolin, A. (1988). In search of eve: Transsexual rites of passage. NY: Bergin \& Garvey.

Bornstein, K. (1994). Gender outlaw: On men, women and the rest of us. NY: Routledge.

Boswell, H. (1998). The transgender paradigm shift towards free expression. In D. Denny (Ed.). Current concepts in transgender identity (pp. 55-6). NY: Garland Pub.

Bradley S. J. \& Zucker, K. J. (1997). Gender identity disorder: A review of the past 10 years. Journal of the American Academy of Child and Adolescent Psychiatry, 36 (7): $872-880$.

Broverman, I. K., Broverman, D. M., Clarkson, D. E., Rosenkrantz, P. S., \& Vogel, S. R. (1970). Sex-role stereotypes, and clinical judgments of mental health. Journal of Counseling and Clinical Psychology, 34, 1-7.

Bower, H. (2001). The gender identity disorder in the DSM: A critical evaluation. Australian and New Zealand Journal of Psychiatry, 35 (1), pp. 1-8.

Brown, L. S. (1994). Subversive dialogues: Theory in feminist therapy. NY: Basic Books.

Brownmiller, S. (1975). Against our will: Men, women and rape. NY: Simon and Schuster.

Buhrich, N. \& McConaghy, N. (1977a). Can fetishism occur in transsexualism? Archives of Sexual Behavior, 6 (3), 223-235.

Buhrich, N. \& McConaghy, N. (1977b). The discrete syndromes of transvestism and transsexualism. Archives of Sexual Behavior, 6 (3), 483-495.

Buhrich, N. \& McConaghy, N. (1979). Three clinically discrete categories of fetishistic transvestism. Archives of Sexual Behavior, 8, 151-157.

Bullough, V. L. (2000). Transgenderism and the Concept of Gender. The International Journal of Transgenderism, 4 (3). Retrieved May 10, 2005, from: http://www. symposion.com/ijt/gilbert/bullough.htm.

Bullough, B. \& Bullough,V. (1993). Crossdressing, sex, and gender. Philadelphia: University of Pennsylvania Press.

Bullough, B. \& Bullough, V. (1997). Are transvestites necessarily heterosexual? Archives of Sexual Behavior, 26 (1), 1-12.

Burana, L., Roxxie \& Due, L. (Eds.) (1994). Dagger: On butch women. SF.: Cleis Press. 
Burke, P. (1996). Gender shock: Exploding the myths of male and female. NY: Anchor Books/Doubleday.

Cantor, C. (2002). Transsexualism-Need it always be a DSM-IV disorder? Australian and New Zealand Journal of Psychiatry, 36, 1, 141-142.

Caplan, P.J. (1995). They say you're crazy. NY: Addison-Wesley Publishing.

Carroll, R. (1999). Outcomes of Treatment for Gender Dysphoria. Journal of Sex Education and Therapy, 24, 128-136.

Chivers, M.L., \& Bailey, J.M. (2000). Sexual orientation of female-to-male transsexuals: A comparison of homosexual and nonhomosexual types. Archives of Sexual Behavior, 29, 259-278.

Clare, D. \& Tully, B. (1989). Transhomosexuality, or the dissociation of sexual orientation and sex object choice, Archives of Sexual Behavior, 18, 531-536.

Coates S. (1990). Ontogenesis of boyhood gender identity disorder. Journal of the American Academy of Psychoanalysis, 18 (3), 414-438.

Coates, S. \& Person, E.S. (1985). Extreme boyhood femininity: Isolated behavior or pervasive disorder? Journal of American Academy of Child Psychiatry, 24 (6), 702-709.

Coates, S., Friedman, R.C. \& Wolfe, S. (1991). The etiology of boyhood gender identity disorder: A model for integrating temperament, development, and psychodynamics. Psychoanalytic Dialogues, 1 (4), 481-523.

Cohen-Kettenis, P.T. (2001). Gender identity disorder in DSM? [Letter to the editor]. Journal of the American Academy of Child and Adolescent Psychiatry, 40, 391.

Cohen-Kettenis, P. \& van Goozen, S. (1997). Sex reassignment of adolescent transsexuals: A follow-up study. Journal of American Academy of Child and Adolescent Psychiatry, 36 (2), 263-271.

Cohen-Kettenis, P.T., Owens, A., Kaijser, V.G., Bradley, S.J., \& Zucker, K.J. (2003). Demographic characteristics, social competence, and behavior problems in children with gender identity disorder: A cross-national, cross-clinic, comparative analysis. Journal of Abnormal Child Psychology, 31, 41-53.

Cole, S. S., Denny, D., Eyler, A. E., \& Salmons, S. L. (2000). Issues of transgender. In L.T. Szuchman, F. Muscarella (Eds.) Psychological perspectives of human sexuality (pp. 149-195). NY: John Wiley and Sons.

Coleman, E. \& Bockting, W. (1988). Heterosexual prior to sex reassignment: Homosexual afterward: A case study of female-to-male transsexual. Journal of Psychology \& Human Sexuality, 12, 69-82.

Coleman, E., Colgan, P., \& Gooren, L. (1992). Male cross-gender behavior in Myanmar (Burma): A description of the Acault. Archives of Sexual Behavior, 21 (3), 313- 321.

Coleman, E., Bockting, W.O., \& Gooren, L. (1993). Homosexual and bisexual identity in sex-reassigned female-to-male transsexuals. Archives of Sexual Behavior, 22, 37-50.

Corbett, K. (1998). Cross-gendered identifications and homosexual boyhood: Toward a more complex theory of gender. American Journal of Orthopsychiatry, 68 (3), 52-360.

Cromwell, J. (1999). Transmen and FTMs: Identities, bodies, genders, and sexualities. Champaign, IL: University of Illinois. 
Cromwell, J., Green, J. \& Denny, D. (2001). The language of gender variance. Paper presented at XVII HBIGDA International Symposium in Gender Dysphoria, Galveston, TX, 31 October-4 November.

Davis, D. L. (1998). The sexual and gender identity disorders. Transcultural Psychiatry, 35 (3), Sept, 401-412.

Daskalos, C.T. (1998). Changes in sexual orientation of six heterosexual male-to-female transsexuals. Archives of Sexual Behavior, 27 (6), 605-614.

D'Emilio, J. (1983). Sexual politics, sexual communities: The making of the homosexual minority in the United States, 1940-1970. University of Chicago Press.

Denny, D. (1992). The politics of diagnosis and a diagnosis of politics: The university-affiliated gender clinics, and how they failed to meet the needs of transsexual people. Chrysalis: The Journal of Transgressive Gender Identities, 1 (3), 9-20.

Denny, D. (2004). Changing models of transsexualism. Journal of Gay \& Lesbian Psychotherapy, 8 (1/2), 25-40.

Denny, D. \& Roberts, J. (1997), Results of a survey of consumer attitudes about the HBIGDA Standards of Care. In: Gender Blending, eds. B. Bullough, V.A. Bullough \& J. Elias. Amherst, NY: Prometheus Books, pp. 320-336.

Devor, H. (1989). Gender blending: Confronting the limits of duality. Bloomington: Indiana University Press.

Devor, H. (1997a). FTM: Female-to-male transsexuals in society. Bloomington: Indiana University Press.

Devor, H. (1997b). Female gender dysphoria: Personal problem or social problem? Annual Review of Sex Research, 7, 44-89. Retrieved May 10, 2005, from: http:// web.uvic.ca/ ahdevor/FEMDYS.html

Devor, H. (1998). Sexual orientation identities, attractions, and practices of femaleto-male transsexuals. In D. Denny (Ed.) Current concepts in transgender identity. (pp. 249- 275). NY: Garland Pub.

Di Ceglie, D., Freedman, D., Mc Pherson, S., Richardson, P. (2002). Children and adolescents referred to a specialist gender identity development service: Clinical features and demographic characteristics. International Journal of Transgenderism, 6 (1). Retrieved May 10, 2005, from: http://www.symposion.com/ijt/ijtvo06no01_01.htm.

Dickey, R. \& Stephens, J. (1995). Female to male transsexualism, heterosexual type: Two cases, Archives of Sexual Behavior, 2 (4), 439-445.

Doctor, R. F. (1988). Transvestites and transsexuals: Toward a theory of cross-gender behavior. NY: Plenum Press.

Doctor, R. F. \& Prince, V. (1997). Transvestism: A survey of 1032 cross-dressers. Archives of Sexual Behavior, 26 (6), 589-605.

Dreger, A. D. (1998) Hermaphrodites and the Medical Invention of Sex. Harvard University Press.

Ehrenreich, B. \& English, D. (1973). Complaints and Disorders: The sexual politics of sickness. NY: The Feminist Press at City University.

Ehrenreich, B. \& English, D. (1978). For her own good: 150 years of the experts advice to women. Garden City, NY: Anchor Press/Doubleday.

Ekins, R. \& King, D. (1998). Blending genders: Contributions to the emerging field of transgender studies. In D. Denny (Ed.). Current concepts in transgender identity (pp. 97-115). NY: Garland. 
Eyler, A. E. \& Wright, K (1997). Gender identification and sexual orientation among genetic females with gender-blended self-perception in childhood and adolescence. International Journal of Transgenderism, 1 (1). Available: Retrieved May 13, 2005, from: http://www.symposion.com/ijt/ijtc0102.htm.

Fausto-Sterling, A. (2000) Sexing the body: Gender politics and the construction of sexuality. NY: Basic Books.

Feinberg, L. (1993). Stone Butch Blues. Ithaca NY: Firebrand Books.

Foucault, M. (1965). Madness and civilization: A history of insanity in the Age of Reason. (trans: Richard Howard). NY: Pantheon Books/Random House.

Foucault, M. (1978). The history of sexuality: An introduction (Vol. 1). NY: Pantheon Books.

Foucault, M. (2003). Abnormal: Lectures at the College de France 1974-1975. (trans: Graham Burchell). NY: Verso.

Freund K., Steiner, B.W., \& Chan, S. (1982). Two types of cross-gender identity. Archives of Sexual Behavior, 8, 527-558.

Gagné, P., Tewksbury, R., \& McGaughey, D. (1997). Coming out and crossing over: Identity formation and proclamation in a transgender community. Gender and Society, 11 (4), 478-508.

Geller, J. L. \& Harris, M. (1994). Women of the asylum: Voices from behind the walls 1840-1945. NY: Anchor Books/Doubleday.

Green, R. (1987). The "sissy boy syndrome" and the development of homosexuality. New Haven, CT: Yale University Press.

Green, J. (2001). The art and nature of gender. In F. Haynes \& T. McKenna (Eds.) Unseen genders: Beyond the binaries (pp. 59-70). NY: Peter Lang.

Green, J. (2004). Becoming a visible man. Nashville, Tennessee Vanderbilt University Press.

Halberstam, J. (1998a). Female masculinity. Durham NC: Duke Press.

Hale, C. J. (1998). Consuming the living, dis(re)memebering the dead in the butch/ftm borderlands, GLQ, 4 (2), 311-348.

Hausman, B. L. (1995). Changing sex: Transsexualism, technology, and idea of gender. Durham, NC: Duke University Press.

Herdt, G. (Ed.) (1994). Third sex third gender: Beyond sexual dimorphism in culture and history. NY: Zone Books.

Herman, J. L. (1992). Trauma and recovery: The aftermath of violence-from domestic abuse to political terror. NY: Basic Books.

Herrnstein, R. J. \& Murray, C. (1994). The bell curve: Intelligence and class structure in American life. NY: The Free Press/Simon and Schuster.

Hooley, J. (1997, January). Transgender politics, medicine and representation: Off our backs, off our bodies. Social Alternatives, 16 (1).

Isay, R. A., (1997, November 21). Remove gender identity disorder from DSM. Psychiatric News, 32 (22), 9, 13.

Johnson, S. \& Hunt, D. (1990). The relationship of male transsexual typology to psychosocial adjustment. Archives of Sexual Behavior, 1 (4), 349-360.

Jones, E. E. (1982). Psychotherapists impressions of treatment outcome as a function of race. Journal of Clinical Psychology, 38, 722-731.

Katz, J. N. (1995). The invention of heterosexuality. NY: Dutton. 
Kennedy, E.J. \& Davis, M.D. (1993). Boots of leather, slippers of gold: The history of a lesbian community. NY: Penguin Books.

Kinsey, A. (1948). Sexual behavior in the human male. Philadelphia: W.B. Saunders Co. Kinsey, A. (1953). Sexual behavior in the human female. Philadelphia: W.B. Saunders Co.

Kirk, S. \& Kutchins, H. (1996). Making us crazy: DSM, the psychiatric bible and the creation of mental disorders. New York: Free Press.

Kremer, J. \& den Daas, H.P. (1990). Case report: A man with breast dysphoria. Archives of Sexual Behavior, 19 (2), 179-181.

Landén, M., Wålinder, J., Lambert, G., \& Lundström, B. (1998). Factors predictive of regret in sex reassignment. Acta Psychiatr Scan, 97, 284-289.

Langer, S.J. \& Martin, J.I. (2004). How dresses can make you mentally ill: Examining gender identity disorder in children. Child and Adolescent Social Work Journal, 21 (1), 5-22.

Långstöm, N. \& Zucker, K.J. (2005). Transvestic fetishism in the general population: Prevalence and correlates. Journal of Sex \& Marital Therapy, 31, 87-95.

Lawrence, A. (2004). Autogynephilia: A paraphilic model of gender identity. Journal of Gay \& Lesbian Psychotherapy, 8 (1/2), 69-88.

Lev, A. I. (1998, October). Invisible gender. In the Family, 8-11.

Lev, A. I. (2004). Transgender Emergence: Therapeutic guidelines for working with gender-variant people and their families. Binghamton, NY: The Haworth Press, Inc.

Lev, A.I. (in press). Transgender Communities: Developing Identity Through Connection. In Bieschke, K., Perez, R., \& DeBord, K. (Eds.) Handbook of counseling and psychotherapy with lesbian, gay, and bisexual clients (2nd ed.). American Psychological Association, Washington, DC.

Levine, S. (1993). Gender-disturbed males. Journal of Sex and Marital Therapy, 19(2), 131-141.

Levine, S. \& Lothstein, L. (1981). Transsexualism or the gender dysphoria syndromes. Journal of Sex and Marital Therapy, 7 (2), 85-113.

Lewins, F. (1995). Transsexualism in society: A sociology of male-to-female transsexuals. South Melbourne, Australia: MacMillian Press.

Loring, M. \& Powell, B. (1988). Gender, race, and DSM-III: A study of the objectivity of psychiatric diagnostic behavior. Journal of Health and Social Behavior, 29, 1-22.

Mallon G.P. (1999). Social services with transgender youth. Binghamton, NY: The Haworth Press, Inc.

McKain, T.L. (1996). Acknowledging mixed-sex people. Journal of Sex and Marital Therapy, 22 (4), 265-279.

Marks, I., Green, R., \& Mataix-Coles, D. (2001). Adult gender disorder can remit. Comprehensive Psychiatry, 41 (4), 273-5.

Meyer, W., Bockting, W., Cohen-Kettenis, P., Coleman, E., DiCeglie, D., Devor, H., Gooren, L., Joris Hage, J., Kirk, S., Kuiper, B., Laub, D., Lawrence, A., Menard, Y., Patton, J., Schaefer, L., Webb, A., \& Wheeler, C. (February 2001). The standards of are for gender identity disorder-Sixth Version. International Journal of Transgenderism, 5 (1). Available: Retrieved May 13, 2005, from: http://www.symposion. com/ijt/soc_2001/index.htm. 
Michel, A., Mormont, C., \& Legros, J. J. (2001). A psycho-endocrinological overview of transsexualism. European Journal of Endocrinology, 145, 365-376.

Miller, D. (1994). Women who hurt themselves: A book of hope and understanding. NY: BasicBooks.

Money, J. \& Lamacz, M., (1984). Gynemimesis and gynemimetophilia: Individual and cross-cultural manifestations of a gender-coping strategy hitherto unnamed. Comprehensive-Psychiatry, 25 (4), 392-403.

Monro, S. (2005). Beyond male and female: Poststructualism and the spectrum of gender. International Journal of Transgenderism, 8 (1), 3-22.

Mowbray, C. T., Lanir, S., \& Hulce, M. (1985). Women and Mental Health: New directions for change (Eds.). Binghamton, New York: Harrington Park Press.

Nestle, J. (1992). The persistent desire: A femme-butch reader. LA: Alyson Press.

Nestle, J., Wilchins, R., \& Howell, C. (2002). GenderQueer: Voices from beyond the sexual binary LA: Alyson Publications.

Newman, L.K. (2002). Sex, gender and culture: Issues in the definition, assessment, and treatment of gender identity disorders. Clinical child psychology and psychiatry, 7(3), 352-259.

Nicolosi, J. (1991). Reparative therapy of male homosexuality: A new clinical approach. Northvale, NJ: Jason Aronson.

O'Hartigan, M. D. (1997). The GID controversy: Transsexuals need the gender identity disorder diagnosis. Transgender Tapestry, 79, 30, 46.

Pauly, I. B. (1992). Terminology and classification of gender identity disorders. In W.O. Bockting, \& E. Coleman (Eds.) Gender dysphoria: Interdisciplinary approaches in clinical management (pp. 1-14). Binghamton, NY: The Haworth Press, Inc.

Person, E. \& Ovesey, L. (1974a). The transsexual syndrome in males I: Primary transsexualism. American Journal of Psychotherapy, 28, 4-20.

Person, E. \& Ovesey, L. (1974b). The transsexual syndrome in males II: Secondary transsexuality. American Journal of Psychotherapy, 28, 174-193.

Person, E. \& Ovesey, L. (1976). Transvestism: A disorder of the sense of self. International Journal of Psychoanalytic Psychotherapy, 5, 221-235.

Person, E. \& Ovesey, L. (1984). Homosexual cross-dressers. Journal of the American Academy of Psychoanalysis, 12, 167-86.

Pharr, S. (1988). Homophobia: A weapon of sexism. (Women's Project). Little Rock, AR: Chardon Press.

Pratt, M.B. (1995). S/HE. Firebrand Books, Ithaca, NY.

Prosser, J. (1998). Second skins: The body narratives of transsexuality. NY: Columbia University Press.

Rachlin, K. (1997). Partners in the journey: Psychotherapy and six stages of gender revelation. Presented at the Second Congress on Sex and Gender, King of Prussia, PA. June.

Rachlin, K. (1999). Factors which influence individual's decisions when considering female-to-male genital reconstructive surgery. International Journal of Transgenderism, 3 (3). Available: Retrieved May 13, 2005, from: http://www.symposion. com/ijt/ijt990302.htm

Raj, R. (2002). Towards a transpositive therapeutic model: Developing clinical sensitivity and cultural competence in the effective support of transsexual and trans- 
gendered clients. The International Journal of Transgenderism, 6 (2). Available: Retrieved May 13, 2005, from: http://www.symposion.com/ijt/ijtvo06no02_04.htm

Rekers, G. A. \& Kilgus, M. D. (1995). Differential diagnosis and rationale for treatment of gender identity disorders and transvestism. In. G. A. Rekers (Ed.) Handbook of child and adolescent sexual problems (pp. 255-271). NY: Lexington Books.

Roback, H. B. \& Lothstein, L. M. (1986). The female mid-life sex change applicant: A comparison with younger female transsexuals and older male sex change applicants. Archives of Sexual Behavior, 15 (5), 401-415.

Robertson, P.K. (2004). The historical effects of depathologizing. The family journal: Counseling and therapy for couples and families, 12, 163-169.

Rosario, V.A. (1996). Trans (homo) sexuality? Double inversion, psychiatric confusion, and hetero-hegemony. In B. Beemyn \& M. Eliason (Eds.) Queer studies: A lesbian, gay, bisexual and transgender anthology (pp. 35-55). NY University Press.

Rosario, V.A. (2004). "Qué joto bonita!": Transgender negotiations of sex and ethnicity. Journal of Gay \& Lesbian Psychotherapy, 8 (1/2), 89-98.

Roscoe, W. (1998). Changing ones: Third and fourth genders in native North America. NY: St. Martin's Press.

Rottnek, M. (Ed.) (1999). Sissies and tomboys: Gender nonconformity and homosexual childhoods. NY: University Press.

Rubin, G. (1992). Of catamites and kings: Reflections on butch gender and boundaries. In J. Nestle, (Ed.) The persistent desire: A femme-butch reader (pp. 466-482). LA: Alyson.

Rubin, H. (2003). Self made men: Identity, embodiment and recognition among transsexual men. Nashville, TN: Vanderbilt University Press.

Schechter, S. (1982). Women and male violence: The visions and struggles of the battered women's movement. Cambridge, MA: South End Press.

Seil, D. (2004). The diagnosis and treatment of transgendered patients. Journal of Gay \& Lesbian Psychotherapy, 8 (1/2), 99-116.

Sell, I. (2001). Not man, not woman: Psychospiritual characteristics of a western third gender. Journal of Transpersonal Psychology, 33 (1).

Shapiro, E. (2004). Transcending barriers: Transgender organizing on the Internet. Journal of Gay and Lesbian Social Services: Special Issue on Strategies for Gay and Lesbian Rights Organizing, 16 (3/4), 165-179.

Socarides, C. W. (1999) Thought reform and the psychology of homosexual advocacy. National Association for Research and Therapy of Homosexuality, Retrieved May 10, 2005, from: http://www.leaderu.com/orgs/narth/1995papers/socarides.html.

Somerville, S. B. (2000). Queering the color line: Race and the invention of homosexuality in American culture. Durham, NC: Duke University Press.

Smith, J. (1988). Psychopathology, homosexuality, and homophobia. In M. W. Ross (Ed.) The treatment of homosexual with mental health disorders (pp. 59-74). Binghamton, NY: The Haworth Press, Inc.

Spade, D. (2003). Resisting medicine: Re/modeling gender. Berkeley Women's Law Journal, 18, 15-37.

Stoller, R. J. (1966). The mother's contribution to infantile transvestic behavior. International Journal of Psychoanalysis, 47, 384-395. 
Stoller, R. J. (1967). "It's only a phase": Femininity in boys. Journal of American Medical Association, 201, 314-315.

Stoller, R. J. (1968a). Sex and Gender (vol. 1): The development of masculinity and femininity. NY: Jason Aronson.

Stoller, R. J. (1968b). Male childhood transsexualism. Journal of American Academy of Child Psychiatry, 7, 193-209.

Stoller, R. J., Marmor, J., Beiber, I., Gold, R., Socarides, C.W., Green, R., \& Spitzer, R.L., (1973). A Symposium: Should homosexuality be in the APA nomenclature? American Journal of Psychiatry, 130, 1207-1216.

Szasz, T. (1970). The myth of mental illness. NY: Doubleday.

Tarver, D. (2002). Transgender mental health: The intersection of race, sexual orientation, and gender identity. In B.E. Jones and M.J. Hill (Eds.) Mental health issues in lesbian, gay, bisexual and transgender communities (pp. 93-108). Review of Psychiatry, American Psychiatric Association, 21.

Tauchert, A. (2001). Beyond the binary: Fuzzy gender and the radical center. In F. Haynes \& T. McKenna (Eds.) Unseen genders: Beyond the binaries (pp. 181-191). NY: Peter Lang.

Vanderburgh, R. (2001). Gender dissonance: A new paradigm. Available: Retrieved May 13, 2005, from: http://www.transtherapist.com/writings/thesis.html.

Wade, J. C. (1993). Institutional racism: An analysis of the mental health system. American Journal of Orthopsychiatry, 63 (4).

Wakefield, J. C. (1997). Diagnosing DSM-IV-Part 1: DSM-IV and the concept of mental disorder. Behavior Research and Therapy, 35 (7), 633-649.

Walinder, J.B., Lundstrom, B., \& Thuwe, L. (1978). Prognostic factors in the assessment of male transsexuals for sex reassignment. British Journal of Psychiatry, 132, 16-20.

Walworth, J. (1997). Sex reassignment surgery in male-to-female transsexuals: Client satisfaction in relation to selection criteria. In B. Bullough, V. L. Bullough \& J. Elias (Eds.) Gender blending (pp. 352-373). Amherst, NY: Prometheus Books.

Whittle, S. (1993). The history of a psychiatric diagnostic category: Transexualism. Chrysalis: The Journal of Transgressive Gender Identities, 1 (5), 25-32, 49.

Whittle, S. (1998). The trans-cyberian mail way. Social \& Legal Studies, 7, 389-408.

Wilchins, R. A. (1997). Read my lips: Sexual subversion and the end of gender. Ithaca, NY: Firebrand.

Wilson, K. (1997). Gender as illness: Issues of psychiatric classification. 6th annual ICTLEP transgender law and employment policy conference, Houston Texas. Available Retrieved May 13, 2005, from: http://www.transgender.org/gidr/ kwictl97.html

Wilson, K. (2002). DSM-IV-TR: Gender identity disorder in adolescents and adults, 302.85, GIDreformorm: Challenging Psychiatric Stereotypes of Gender Diversity [Online] Available: Retrieved May 13, 2005: http://www.gidreform.org/gid30285. html

Wilson, K.K. \& Hammond, B.E. (1996). Myth, stereotype, and cross-gender identity in the DSM-IV. Paper presented at the Association for Women in Psychology's 21st Annual Feminist Psychology Conference, Portland, OR. 
Weiss, J.T. (2004). The cutting edge of employment diversity: Trangender human resources policies in U.S. employers (Dissertation Manuscript). The Law, Policy, and Society Program. Available: Retrieved May 13, 2005, from: http://phobos. ramapo.edu/ jweiss/dissertation.pdf.

Wise, T. \& Meyer, J. (1980). The border area between transvestism and gender dysphoria: Transvestic applicants for sex reassignment. Archives of Sexual Behavior, 9, 327-342.

Zucker, K. J. (1990). Treatment of gender identity disorder in children. In Blanchard, R. \& Steiner, B.W. (Ed.). Clinical management of gender identity disorders in children and adults (pp. 24-45). Washington, DC: American Psychiatric Association.

Zucker, K.J. (2005). Was the gender identity disorder of childhood diagnosis introduced into the DSM-III as a backdoor maneuver to replace homosexuality? Journal of Sex and Marital Therapy, 31 (1), 31-41.

Zucker, K. \& Bradley, S.J. (1995). Gender identity disorder and psychosexual problems in children and adolescents. NY: Guilford Press.

Zuger, B. (1970). The role of familial factors in persistent effeminate behaviors in boys. American Journal of Psychiatry, 126, 1167-1170.

Zuger, B. (1984). Early effeminate behaviors in boys: Outcome and significance for homosexuality. Journal of Nervous and Mental Disease, 32, 449-63. 